\title{
The face-detection effect
}

\author{
DEAN G. PURCELL \\ Oakland University, Rochester, Michigan \\ and \\ ALAN L. STEWART \\ Stevens Institute of Technology, Hoboken, New Jersey
}

\begin{abstract}
We found that briefly flashed pictures of a face were detected more accurately than was a control pattern with a nose, a mouth, and a pair of eyes positioned arbitrarily so that they did not form a face. It has been known for some time that a face, as an organized set of features, is remembered more easily than is any one of its isolated features. Our results show that the perceptual superiority of faces extends to detection tasks, in which there is no need to remember any aspect of the face.
\end{abstract}

A letter of the alphabet, a clearly drawn oblique line, or a facial feature often becomes a more effective stimulus when it is part of a larger, perceptually more coherent pattern. Examples of such context effects are the wordsuperiority effect, the object-superiority effect, and the face-superiority effect. The object-superiority effect occurs when a line is contained within a line drawing. When the drawing is seen as a three-dimensional figure, the embedded line is identified with greater accuracy than when the same line is part of a drawing that appears to be a nondescript, two-dimensional pattern (Weisstein \& Harris, 1974; Williams \& Weisstein, 1984). With the word-superiority effect, a letter of the alphabet is identified more accurately when it is part of a word than when it is part of a string of letters that do not form a word (Reicher, 1969; Wheeler, 1970). The word-superiority effect occurs even when the observers know that the target letter will be one of only four letters that make up the stimulus set and even when the target letter will appear in the word or the letter string, and when the design of the experiment eliminates any advantage the observer might have from guessing (Purcell \& Stanovich, 1982).

A face-superiority effect has also been documented (Homa, Haver, \& Schwartz, 1976; van Santen \& Jonides, 1978). In the study by Homa et al. (1976), observers were presented either with a picture of a face or with the same features rearranged so that they were no longer seen as a face. Subjects were better able to identify a feature on a subsequent trial if it had been seen first as part of a face rather than as part of an arbitrarily arranged pattern of features. Just as with the object-superiority effect and the word-superiority effect, the target item is more easily

D. G. Purcell's mailing address is: Department of Psychology, Oakland University, Rochester, MI 48063. A. L. Stewart's address is: Management Department, Stevens Institute of Technology, Hoboken, NJ 07030. recognized when it is a component of a more coherent pattern.

All previous work on perceptual context effects has required that observers identify the target item. They must name a particular letter of the alphabet or identify a specific facial feature, such as a nose or an eye, that was presented on a previous trial. Identifying a particular object is a complex task, requiring detailed visual information. Detection, however, requires only rudimentary visual information; it simply involves responding to any change in the visual field (Dember \& Warm, 1979). The observer has only to indicate whether or not something, anything at all, was present during the stimulus presentation interval.

To date, no one has shown that context effects can make a target item more detectable. A series of studies conducted in our laboratories has uncovered what we believe is a context effect using a detection task (Purcell \& Stewart, 1981; Purcell, Stewart, Botwin \& Kreigh, 1983). In our studies, a subject was merely asked to perform a forced-choice detection of either the temporal interval or the spatial location in which any change occurred in the spatial contrast of the target field.

The types of facial stimuli that we investigated fell into two classes. One class of stimuli consisted of conventional representations of faces, either pictures or schematic drawings. The other class of stimuli consisted of faces that had been distorted by rearranging the individual features. Our data indicate that the conventional representations yielded a shorter duration threshold than did a collection of identical but rearranged facial features when the offset of the target was followed immediately by a patterned masking stimulus. In complementary experiments, when the duration of a target stimulus was fixed, and the interval separating the offset of the target from the onset of a patterned masking stimulus was varied, we found that normal faces were detected more readily than were rearranged facial stimuli for any given interstimulus interval. 
These data represent what we refer to as the face-detection effect: the visual context of the arrangement of the individual features of the stimulus affects the ability of an observer to determine whether a stimulus is present or not. Thus, although it has been known for some time that context effects influence recognition and recall, our data indicate that context effects can even influence a person's ability to determine whether a stimulus is present.

In our previous work with the face-detection effect, we followed the offset of the stimulus with a patterned masking stimulus to control the amount of time the observers had to process the stimulus. If duration thresholds for detecting the facial stimulus were determined without following the offset of the stimulus with a patterned mask, we failed to find a face-detection effect (Purcell \& Stewart, 1981). In the present study, we sought to determine whether the face-detection effect might be restricted to masking paradigms where a patterned mask is used. We wanted to see whether or not such effects would be found when the offset of the target was followed by a homogeneous flash of light as the masking stimulus. Accordingly, we designed this study to compare the observer's ability to detect the presence of a stimulus when its offset was followed either by a patterned masking stimulus or by a homogeneous flash of light.

\section{METHOD}

\section{Apparatus and Stimuli}

The target stimulus was a black-on-white picture of a face taken from a newspaper photograph and reproduced with a Xerox copy machine. Several copies were made, and of these, only those Xeroxed pictures that appeared to be identical in darkness and detail were used as stimuli. Even so, each Xerox picture was assigned randomly to the experimental condition for which it was the stimulus. Two versions of this face were created; one stimulus was the normal face, and the second stimulus was made up of repositioned facial features. We referred to this stimulus as a scrambled facial stimulus. For the scrambled face, the nose replaced the left eye, the right three fourths of the mouth replaced the right eye, the left eye replaced the nose, the right eye replaced the left one fourth of the mouth, and the left one fourth of the mouth replaced the right three fourths of the mouth. Although the features were rearranged in the scrambled stimulus, they maintained their normal, upright orientation, as did the outline of the head itself.

The hair and neck were trimmed from both the normal and the rearranged facial stimuli so that the features, other than the outline of the head, consisted of only the eyes, the nose, and the mouth. It is important to note that care was taken in selecting stimuli so that the hair did not provide a large, dark, distinct stimulus. Such a large-scale feature might be so perceptually potent as to obscure the part played by the organizational properties contributed by properly positioned facial features. The pictures were mounted on white index cards. The outline of the face was apparent on close inspection, but its contrast was slight, and it was no longer visible when exposed for $100 \mathrm{msec}$ or less.

The stimuli both subtended a visual angle of approximately $1^{\circ}$ in height and $1.25^{\circ}$ in width. A two-alternative, spatial forced-choice detection procedure was used. The facial stimuli were positioned so that their inner edge was approximately $.5^{\circ}$ right or left of a central black fixation point. The fixation point subtended $.13^{\circ}$. Both the patterned masking stimulus and the flash masking stimulus were centered on the fixation point. The patterned mask consisted of the overlapping capital letters $N$ and $O$. This pattern of letters subtended approximately $3.2^{\circ}$ in height and $6^{\circ}$ in width, and was presented within a square illuminated field, $8^{\circ}$ on each side.
The flash mask consisted of a homogeneously illuminated square field subtending $8^{\circ}$ of visual arc on each side. The luminance of the continuously exposed $8^{\circ}$ square fixation field was set at approximately $1.7 \mathrm{~cd} / \mathrm{m}^{2}$. The luminance of the masking field was set at $41 \mathrm{~cd} / \mathrm{m}^{2}$. The luminance of the target field was set at $48 \mathrm{~cd} / \mathrm{m}^{2}$ when the pattern mask was used, and was decreased to $17.7 \mathrm{~cd} / \mathrm{m}^{2}$ (by means of a neutral density filter) when the flash mask was used. The luminance of the target field was lower for the flash masking condition, so that the inherently less potent flash masking stimulus produced an interference effect comparable to the patterned masking stimulus. The target field subtended $8^{\circ}$ unless the filter was in place; with the filter present, it subtended $5^{\circ}$. All stimuli were presented via an Iconix four-channel tachistoscope. The control of the stimulus durations and presentations was under the control of an Apple II+ computer which was interfaced with the tachistoscope by means of a Cognitive Testing Station card supplied by Digitry Inc. The experiment was conducted in a lighted room whose walls reflected approximately $2.6 \mathrm{~cd} / \mathrm{m}^{2}$. The exposure duration of both masking stimuli was set at $100 \mathrm{msec}$. The exposure duration of the facial stimuli (normal and scrambled) was the dependent variable. The mask onset was coincident with the offset of the target.

\section{Procedure}

Eighteen observers from an introductory psychology class at Oakland University volunteered to participate in the study. The subjects' task was to indicate to which side of the fixation dot the stimulus was presented. Subjects indicated this by pressing one of two buttons, one on the right for the right side and one on the left for the left side. Subjects initiated each trial upon hearing a signal tone from the computer.

The detection threshold for each of the four experimental conditions was determined with the Best PEST algorithm (Lieberman \& Pentland, 1982; the code was implemented in Apple Pascal). Conditions of mask type (pattern or flash of light) were run within counterbalanced blocks. Within each block, each face type (normal or scrambled) occurred in random order until 40 trials had been run with each face type. Half the subjects were run first under conditions using the patterned masking stimulus. The other half of the subjects were run first under flash masking trials. In addition to presenting the face type in random order, the position of a given face (right or left of fixation) was also randomly determined.

Subjects practiced with patterned and flash masking stimuli immediately before the corresponding trials were run. This practice emphasized that the target was present on each trial, although its location varied randomly between one of two fixed locations known to the subject. The subjects were instructed to make a response on each trial, even if they did not think that they saw the stimulus and had to guess. And, indeed, most subjects reported at the end of the experiment that they seldom, if ever, saw a clear representation of a face. A complete session took $1 / 2 \mathrm{~h}$.

\section{RESULTS}

Under masking by a patterned stimulus, the average threshold duration for detecting the location of the normal face was $18 \mathrm{msec}$ shorter than that for detecting the location of the scrambled face ( $38 \mathrm{msec}$ vs. $56 \mathrm{msec}$ ). Under masking by a flash of light, the threshold differences between normal and scrambled facial stimuli were only $4 \mathrm{msec}(22 \mathrm{msec}$ vs. $26 \mathrm{msec})$. This trend was reflected in the analysis of variance, where the order of the masking condition was a between-subjects variable, whereas the mask type and face type were within-subjects variables. The difference in duration between types of face (normal vs. scrambled) was statistically significant $[F(1,16)=43.12, p<.001]$, as were the type of mask (patterned vs. flash) $[F(1,16)=37.09, p<.001]$ and the interaction of the type of face and the type of masking stimulus $[F(1,16)=30.03, p<.001]$. 


\section{DISCUSSION}

This study supports our previous work demonstrating that a process as simple as visual detection can be affected by the organization of a stimulus. It also indicates that the effect is more pronounced under masking by a patterned stimulus than under masking by a flash of light. Indeed, the present study suggests that the effect may be absent under flash masking. The word-superiority effect has been obtained with a patterned masking stimulus. A much smaller effect was obtained with a flash mask (Johnston \& McClelland, 1973). Only future research can determine whether this is more than a coincidence.

Weisstein, Williams, and Harris (1982) obtained an object-superiority effect without using a masking stimulus. With their procedure, however, the subject was required to identify the target. It may be that with simple detection tasks, visual context effects can only be produced with masking paradigms which use a patterned masking stimulus. But this is speculation. Our main result is clear, however. By the application of a forced-choice detection procedure, we have been able to demonstrate a context effect which influences the most basic level of perceptual processing-the detection of the presence of a stimulus.

\section{REFERENCES}

Dember, W. N., \& WARM, J. S. (1979). Psychology of perception. New York: Holt, Rinehart \& Winston.

Homa, D., Haver, B., \& Schwartz, T. (1976). Perceptibility of schematic face stimuli: Evidence for a perceptual gestalt. Memory \& Cognition, 4, 176-185.

Johnston, J. C., \& MCCLELland, J. L. (1973). Visual factors in word perception. Perception \& Psychophysics, 14, 365-370.
Lieberman, H. R. , \& Pentland, A. P. (1982). Microcomputer-based estimation of psychophysical thresholds: The Best PEST. Behavior Research Methods \& Instrumentation, 14, 21-25.

Purcell, D. G., \& Stanovich, K. E. (1982). Some boundary conditions for a word superiority effect. Quarterly Journal of Experimental Psychology, 34, 117-134.

Purcell, D. G., \& Stewart, A. L. (1981). A face superiority effect. Bulletin of the Psychonomic Society, 18, 73. (Abstract)

Purcell, D. G., Stewart, A. L., Botwin, M., \& Kreigh, R. (1983). A face superiority effect: Hemiretina effects. Bulletin of the Psychonomic Society, 21, 351. (Abstract)

REICHER, G. M. (1969). Perceptual recognition as a function of meaningfulness of stimulus material. Journal of Experimental Psychology, 81, 275-280.

VAN SANTen, J. P. H., \& Jonides, J. (1978). A replication of the facesuperiority effect. Bulletin of the Psychonomic Society, 12, 378-380.

WeISSTEIN, N., \& HARRIS, C. S. (1974). Visual detection of line segments: An object superiority effect. Science, 186, 752-755.

Weisstein, N., Williams, M. C., \& Harris, C. S. (1982). Depth, connectedness, and structural relevance in the object-superiority effect: Line segments are harder to see in flatter patterns. Perception, 11, 5-17.

WheEler, D. D. (1970). Processes in word recognition. Cognitive Psychology, 1, 59-85.

Williams, M. C., \& Weisstein, N. (1984). The effect of perceived depth and connectedness on metacontrast functions. Vision Research, 24, 1279-1288.

(Manuscript received for publication October 26, 1985.) 